\title{
Bloom's Taxonomy for Standardizing BPM Education of IT Under-Graduates Students
}

\author{
Muhammad Anwar-ur-Rehman Pasha \\ Professor of IT \& Chairman \\ Department of CS \& IT \\ University of Sargodha
}

\author{
Shaheen Pasha \\ Assistant Professor \\ Division of Education \\ University of Education, Lahore
}

\begin{abstract}
The multidimensional challenges of the $21^{\text {st }}$ century have forced organizations to develop more sophisticated process management capabilities for maintaining a high level of transparency, efficiency, agility, and control. BPM has emerged as a powerful tool offering a set of structured methods and technologies to implement on-going crossfunctional process management. This puts process modeling capabilities among the most in demand skills in the IT employment market. Consequently, many institutions around the globe started offering degree/training programs in BPM. Yet no consensus has emerged regarding the contents of these academic programs. Taking into account the inherent connections of BPM concepts with IT education and the emerging employment rolls of IT graduate, this paper presents Bloom's taxonomy based learning objectives which may help instructors/institutions to standardize the contents of BPM education of IT under-graduates students.
\end{abstract}

\section{General Terms}

Business Process Management, Business Process Management Education, BPM capabilities, Bloom's Taxonomy

\section{Keywords}

Business Process Management Education, Bloom's Taxonomy for BPM Education, BPM capabilities, Relationship between BPM and IT.

\section{INTRODUCTION}

The $21^{\text {st }}$ century is loaded with multidimensional challenges like, competing in a globalized business environment [1], keeping pace with innovative technologies [2], managing exponentially growing information with respect to nature, speed, volume, time, and mode [3], controlling interorganizational and intra-organizational business processes in real time $[4,5,6]$, optimizing business processes across multisite workplaces [7], etc. Some other challenges causing a new level of competition concerning skill, quality, and productivity $[8,9]$ include social \& cultural diversity, rapidly changing products and processes, a highly uncertain and chaotic global business environment, etc. These challenges have forced organizations to develop a high level of innovation and more sophisticated process management capabilities $[10,11]$.

In today's knowledge driven economies, processes are considered critical assets of organizations as they are central to every activity that organizations perform to improve their efficiency, productivity, agility, and sustainability. These processes can be of different types e.g., knowledge-intensive, complex, tightly coupled with each other, embedded within the procedures and policies. Some processes exist in the form of individual and collective tacit knowledge, and some may embrained within the organizations' communities of practice. For organizations, efficient process management has become essential to enhance their performance and decision making capacity. Consequently, organizations increasingly focus on a process view of management for maintaining a high level of agility, control, and transparency [12].

The ability to run the business economically and efficiently without compromising quality and customer satisfaction is crucial for progressive organizations. Yet, multi-location organizations face challenges of process replication at different geographic locations. This duplication affects customer services and puts extra financial liabilities as each discrete unit tackles these functions independently [13]. For this, organizations prefer to implement cross-functional processes management approaches instead of managing loosely connected functional components. A holistic approach for cross-functional process management helps organizations to be agile and efficient $[14,15,16,9]$. The integrated and comprehensive view on business processes was suggested by Michael Porter who introduces the concept of value chain [17]. He highlighted the importance of streamlining operations across various functional units. Later on, Business Process Re-engineering (BPR) emerged as a new wave to enhance organizational efficiency and/or add value. Unfortunately, BPR has failed to produce the desired results as it is a radical, revolutionary, and a one-time undertaking [18].

In recent years, Business Process Management (BPM) has gain popularity among the business community as a powerful competitive tool $[19,20]$. BPM offers a set of structured methods and technologies to implement on-going crossfunctional process management. An increasing number of organizations are trying to embrace BPM. The importance of BPM has also been realized in IT Industry. Barjis [21] has pointed out that poor process modeling causes the failure of many software projects. In the early day's data modeling was the key activity in developing information systems as the focus was on information storage and retrieval. Due to datadriven approaches, business processes were re-engineered to meet technology needs [22]. New management strategies like, Total Quality Management, ISO Standards, Six Sigma, Process-Reengineering, Knowledge Management, etc. exemplifies the emphasis on processes [23]. As a result, the IT industry starts focusing on a more process driven approach and starts developing generic software based on process design for managing operational business processes [22]. This trend has increased the demand of BPM professionals and put process modeling capabilities among the most in demand skills in the IT employment market [24]. 
Realizing the importance of BPM capabilities, many universities and professional bodies around the globe have started offering degree and training programs in BPM [25, 26, 27]. Yet, no consensus has emerged in defining a common definition, scope, meaning and body of knowledge. Henceforth, different universities and professional bodies use different approaches and contents to strengthen students' BPM capabilities. Nevertheless, a standardize curriculum is required to maintain the quality of BPM educational programs. In the academic world, two approaches are commonly used for developing a standardized curriculum : (i) Bottom-up [28], (ii) Top-down [29]. The Bottom-up approach liberates teachers to choose the contents for their courses. In contrast, the Top-down approach demands from teachers to follow the defined learning objectives of the course. The Topdown approach is commonly recommended for maintaining quality and follow standards.

Setting up measurable learning objectives of a course is an important aspect of the Top-down approach. It helps teachers to select appropriate contents, activities and assessment techniques to their courses. Bloom's Taxonomy is commonly advocated for setting up the learning objectives of a course. It allows teachers to describe students' degree of understanding, the application of knowledge, and the demonstration of particular skills. Bloom's Taxonomy can also be used to define the level to which teachers want to develop their students' attitudes, values, and interests [30]. Bloom's Taxonomy has been used in many disciplines but research on the application of Bloom's Taxonomy in the teaching of BPM contents has not been done much. In this paper we have addressed this aspect and presented a set of learning objectives to standardize BPM education for IT undergraduates students. Although the scope of our research is narrow, it may provide strong bases to understand the inherent connections of BPM concepts and practices with IT curriculum for standardizing the course contents for a BPM course. The work presented in this paper is a supplement work carried out in connection with the longitudinal study reported in [31].

\section{BUSINESS PROCESS MANAGEMENT}

BPM is an emerging field of study which has grown steadily over recent years. It is creating a noticeable impact on both academic as well as technology driven business world. Although many definitions of BPM are available in literature, we have adopted The Association of Business Process Management Professionals (ABPMP)'s [32]definition, which defines BPM as: “ $\ldots$ a disciplined approach to identify, design, execute, document, monitor, control, and measure both automated and non-automated business processes to achieve consistent, targeted results consistent with an organization's strategic goals." ABPMP further defines "It [BPM] involves the deliberate, collaborative and increasingly technology-aided definition, improvement, innovation, and management of end-to-end business processes that drive business results, create value, and enable an organization to meet its business objectives with more agility".

In recent years, BPM has emerged as an effective technological solution for cross-functional business processes management [33]. Beimborn \& Joachim's [34] study has reported positive impact of BPM technologies on business process quality. BPM has a wide domain of application; some examples from the IT domain includes BPM in process aware systems [35], BPM in service oriented architecture [36, 37, 38], BPM in Web services [39], etc.

Currently, a broad spectrum of BPM technologies are available in the market offering a variety of functionalities, processes, analytical and collaboration tools for developing process oriented applications. These technologies allow organizations to automate various processes to maximize their existing technology and human infrastructure. This way they can free human resource to add value elsewhere within the organization [40].

BPM technologies have gain popularity among the business community. According to McDonald \& Nunno [41] estimation the total BPMS software market in 2007 has reached $\$ 1.7$ billion. They predict BPM to be one of the fastest-growing segments in the software market and will remain growing during the next five years. TechNavio's report on 'the Global Business Process Management Software Market 2011-2015' forecasts that the global BPM software market will grow at a CAGR of 12.9 percent over the period 2011-2015. Gartner studies [42] have identified business process improvement as the number one business and technology priority of CIOs in 2010. The applications of BPM in multidimensional domains have raised the need of process management capabilities \& expertise. Organizations are looking for workers who have the capabilities to identify and document organizational business processes for process analysis, performance measurement, improvement, or redesign [43].

\section{SCOPE OF BPM IN IT JOB MARKET}

The emergence of BPM has introduced new roles and responsibilities at different levels [44]. For example, Eicker, et. al. [45] discuss six roles in business process management: BPM project leader, process consultant, process owners, process coordinator, process controller, and the process staff. ABPMP has identified twelve roles: "Business Process Analyst, Business Process Engineer, Business Process Architect, Business Process Manager, Business Process Consultant, Business Process Manager, Business Process Owner, Business Analyst, Business Systems Analyst, Manager or Director of Business Performance Improvement, Manager or Director of Business Process Innovation, Process Owner, and Process Officer". Below we have identified some prospective roles for IT graduates demanding BPM capabilities.

- Senior Executive/Project Managers. Being in the leadership role of a software development team they need to analyze the strengths, weaknesses, and governance structure/hierarchy of exiting processes and take decisions to discard redundant processes those are causing performance barriers. They also need to make decisions to introduce new processes with appropriate governance structure to improve performance. For such tasks they need to have capabilities like process analysis, process governance, process portfolio management, etc. In addition, they need to have an understanding of the various aspects of technology infrastructure, organizational processes, process management, and information management systems.

- Business Process Analysts. For an effective requirement elicitation for developing a process oriented software design, they are responsible of identifying, analyzing, evaluating, prioritizing, and documenting the existing processes; conducting 
functional impact analysis of existing and newly proposed processes for changes; developing business scenarios; defining and documenting processes and related functional requirements; defining strategy for process improvements; participating in the preparation of functional specifications and design prototypes. For this purpose, they need to have an understanding of the organizational process or the business unit for which they are working for. To perform their assignment they need to have knowledge about process analysis, process documentation, process improvement techniques \& patterns, processes modeling. They also need to be conversant with information systems, workflow systems, BPMN and BP modeling tools \& technologies, inter-process messaging protocols, human-process interaction, enterprise service bus, etc.

- BPM System Analyst. They are required to analyze complex business requirements, translate these requirements into detailed functional specifications, devise efficient processes, and develop effective technology solutions to meet the organization's business requirement. They also need to provide technical guidance and assist in the business process reengineering for integrating new technologies. They participate in the development and evaluation of organizational BPMS. For this purpose they need to have a deep understanding of computing aspects, technology platforms, information systems, process design, modeling and implementation, user interface design, systems integration, etc. They also need to have up-to-date information about technology, trends, and standards of software industry, the knowledge of BPMN and the technical capabilities of BPMS and ancillary technologies.

- BPM System Developers \& Integrators. They are involved in translating the process specifications, documented by the system analysts, into a new system. They identify functional and technical interface specifications and standards, identify and resolve hardware and software interface issues, coordinate identification of input/ output parameters, lead system integration strategies and design efforts, and provide input to technical integration documentation. Besides organizational processes and BPM knowledge they need to have expertise in computer programming, software design, implementation and deployment methodologies, domain specific and software development standards, software system development, project management.

\section{RELEVANCE OF BPM WITH IT AS AN ACADEMIC DISCIPLINE}

As an academic discipline, BPM is passing through an evolutionary period. It has evolved from two parallel strands: management and technology. From management strand BPM follows 1980's management guru Geary Rummler who advocates for a customer-centric end-to-end process approach and suggests managing those areas which get in the way of efficiency and customer satisfaction. This approach is gaining momentum. An increasing number of organizations have started developing end-to-end process models for potential improvement through analyzing and documenting their key business processes [46].

From technology strand, BPM has emerged from the workflow wave of the nineties. Taking into account the extended role of IT in organizational, in his paper W.M.P. van der Aalst [47] defines BPM as: "Supporting business processes using methods, techniques, and software to design, enact, control, and analyze operational processes involving humans, organizations, applications, documents, and other sources of information". Further to this Vickesh Dhookie [48] considers that BPM unifies the previously distinct disciplines of Process Modeling, Simulation, Workflow, Enterprise Application Integration, and Business to Business integration into a single organizational platform or infrastructure.

As an academic discipline BPM is gaining popularity among the academic community. It is offered in many universities across the globe [28]. Professional associations like the OMG Group and ABPMP have offered business process certifications. Delavari [49] gives an overview and comparison of courses offered in Australia. Bandara et. al. $[25,26]$ discuss the status and challenges of BPM education. In their book related to various approaches of enterprise systems, Targowski et al. [50] also discuss the scope of BPM. Jæger et al. [51] discuss the teaching of business process concepts using enterprise systems in a globalized context. Pal $\&$ Sen [52] examine the relevance of BPM course in business school curriculum. Similarly, Recker, et al. [53] emphasize on the teaching business process modeling.

\section{CHALLENGES OF BPM EDUCATION}

Although, BPM education is gaining popularity globally, academic and training activities related to BPM are not common in Pakistan. Pasha [31] has reported a longitudinal study carried out to investigate the scope, relevance and benefits of teaching a BPM course to undergraduate IT students. The study concludes that BPM concepts and practices have very strong connections with the IT body of knowledge, but the existing curriculum of undergraduate IT programs pays insufficient attention to BPM concepts including, process modeling, design, management, improvement, and inter-organizational processes, etc. The study made recommendations to incorporate BPM body of knowledge in IT undergraduate degree programs' curriculum.

Many recent studies have identified some other common aspects causing problems regarding BPM education. These aspects include lack of textbooks and teaching materials, lack of appropriate BPM skilled professionals in the field, lack of appropriate expertise in the field, lack of resources and opportunities to develop BPM expertise [31, 35, 54, 55, 56]. Although the ABPMP has published the BPM core body of knowledge, but the evolving nature of BPM and associated technologies make it difficult to develop a consensus of what BPM really entails. Academia finds it a challenging to design a standardized BMP curriculum which intends to teach students how to integrate people, technology and processes to produce an agile organization solution.

\section{BLOOM'S TAXONOMY FOR EDUCATIONAL OBJECTIVES}

In 1956, Benjamin Bloom [56] defined taxonomy for the classification of learning objectives within an educational setting. Bloom defines six major categories in the cognitive domain: ( i) Knowledge, (ii) Comprehension, (iii) Application, (iv) Analysis, (v) Synthesis, and (vi) Evaluation. In 2000, Anderson, et. al. [57] revised the taxonomy with a new assembly to make it more relevant for 21 st century 
students and teachers. The revised version renamed the knowledge categories and introduced a new category "Metacognitive Knowledge" which involves knowledge about cognition in general as well as awareness of and knowledge about one's own cognition. The structure of knowledge dimensions of the revised Bloom's Taxonomy include: (i) Factual Knowledge, (ii) Conceptual Knowledge, (iii) Procedural Knowledge, and (iv) Meta-cognitive Knowledge

In the revised version, the noun form of Application, Analysis, and Evaluation is replaced with verb form Apply, Analyze, and Evaluate; whereas, Evaluation \& Comprehension is replaced with Create \& Understand.

One key advantage of Bloom's Taxonomy is that it provides a multi-tiered scale to set the educational objectives required to be achieved as students' learning outcomes. These goals can be of three types: (i) knowledge-based goals, (ii) skills-based goals, and (iii) affective goals related to values, attitudes, and interests. In an educational environment, Bloom's Taxonomy provides a convenient way to describe students' degree of understanding, application of knowledge, and demonstration of particular skills. It can also be used to define the level to which teachers want to develop their students' attitudes, values, and interests [58]. Consequently, teachers feel ease in selecting appropriate contents, activities and assessment methods for their courses. Bloom's Taxonomy has been used in many disciplines but research on the application of Bloom's Taxonomy in teaching BPM contents has not been done much. Using Bloom's Taxonomy, this paper has outlined the course objectives of a BPM course for under-graduate IT students. It is believed that these objectives will help academia to standardize the BPM curriculum.

\section{LEARNING OBJECTIVES OF A BPM COURSE}

Learning objectives are one of the most important building blocks of any educational program. In higher education, a range of terms are used to describe what learners should achieve at the end of a course/program, like aims, goals, learning outcomes, learning objectives, etc. In this paper, we have adopted the term "learning objectives" to state the observable and measurable behaviours which learners should exhibit at the end of a course/program.

Defining learning objectives offers multiple advantages, including

- Make learners aware of what they should achieve

- Help teachers to select appropriate contents and associated pedagogy to help learners to achieve

- Help teachers to select appropriate assessment and evaluation methods to check what learners have achieved

- Help Administration to evaluate quality

Defining learning objectives also help teachers to implement Biggs' constructive alignment [59] which advocates for establishing a harmonious association among the contents, pedagogy, and assessment methods to achieve the specified objectives of the course/program. As explained in the previous section, Bloom's Taxonomy provides a multi-tiered scale to set the educational objectives required to be achieved as students' learning outcomes. For the effective teaching of BPM course following learning objectives are suggested depending on various levels of the course which learners are expected to achieve.

\section{Cognitive (Knowledge objectives)}

- Have knowledge of the history, scope, career path, capabilities, and key concepts of business processes, BPM notations, BPM strategies, BPMS and associated technologies.

- Be aware of various types of process frameworks and predict their behavior and output.

- Have knowledge of various BP modeling techniques, BPM standards, process improvement methodologies.

- Have knowledge of the Extensible Process Definition Language (XPDL), Business Process Modeling Language (BPML), and Business Process Execution Language.

- Have knowledge of performance metrics, balanced scorecard, value added activities, continuous flow, reduction of handoffs, proactive quality assurance, process redesign / reengineering, activity based costing simulation, activity based management, process portfolio, etc.

\section{Psychomotor (Skills objectives)}

- Be able to identify key components, processes, activities in a system and recognize their role in a value chain.

- Be able to develop different processes, identify similarities and differences among various processes and understand hidden knowledge.

- Have skill of relating knowledge from other areas to develop their own models of the world.

- Be able to develop different process models using process modeling tools, techniques \& BPM notations.

- Be able to apply various types of analysis techniques including As-is and To-be process gap analysis, continuous monitoring vs event-triggered analysis, statistical analysis.

\section{Affective (Attitudinal objectives)}

- Have the ability to forecast the impact of process changes on organizational performance.

- Have the ability to critically evaluate and justify their decisions.

- Have the aptitude to manage various aspects of BPM projects including the development \& deployment of BPM project team.

As discussed in the previous section, Anderson, et. al. have revised the Bloom's taxonomy with a new assembly to make it more relevant for 21 st century students and teachers. It is believed that the revised taxonomy is more appropriate for setting the learning objectives of BPM course. According to revised taxonomy knowledge objectives are listed below:

\section{Remember}

A student could recognize and recall:

- History, scope and career path of BPM

- Types, nature, and the importance of business processes with respect to time and space.

- Different types of BPMS and technologies like BPMD, Workflows, Flowcharting, and UML.

- Definitions and specifications of concepts like Analytical Techniques, eBusiness Architectures, Knowledge Management, Business and IT alignment, BPMN systems, Process Mining, Process Modeling, Process Analysis, Process Design and Improvement, BPM Strategy, Business Intelligence, SOA, and ERP systems. 
- Scope of Extensible Process Definition Language (XPDL), Business Process Modeling Language (BPML), and Business Process Execution Language.

- Key capabilities of BPMS.

\section{Understand}

A student should interpret, exemplify, classify, summarize, infer, compare, and explain the following concepts:

- Various types of business processes, BPM notations, and BPM strategies.

- Various types of process management frameworks and maturity models like VRM, BAM, eTOM, SCOR, ITEPF, and CMMI.

- Various types of process improvement methodologies like TQM, Knowledge Management, Lean, PDCA tool and Six Sigma (DMAIC, DFSS) techniques and EFQM Excellence Model (RADAR matrix).

- Various type of analysis techniques including As-is and To-be process gap analysis, continuous monitoring vs event-triggered analysis, statistical analysis.

- Performance metrics, balanced scorecard, value added activities, continuous flow, reduction of handoffs, proactive quality assurance, process redesign / reengineering, activity based costing simulation, activity based management, process portfolio, etc.

- Managing various aspects BPM projects including BPMS development, development \& deployment of BPM project team, development of rollout plan.

\section{Apply}

A student should be able to execute and implement the following concepts in a given situation. It includes

- Apply information, methods, concepts, theories and techniques of BPM for process analysis, process modeling, process design and improvement

- Develop BPM strategy and implement process management.

- Develop models for As-is and To-be process using BPMN.

- Apply appropriate BPM Technology and Architecture.

- Perform activity based costing simulation, continuous monitoring vs event-triggered analysis, and statistical analysis.

- Identify components of a system and able to document them.

- Implement process design principles like value added activities, continuous flow, reduction of handoffs, proactive quality assurance, etc.

- Design performance metrics and decide what, when, and how much to measure.

- Redesign / Reengineer processes and use process improvement methodologies.

- Develop a project team and a rollout plan and manage BPM projects.

- Develop a process portfolio.

- Develop, configure and manage a BPMS.

- Run process performance assessment and reviews.

- Develop BPMS using Extensible Process Definition Language (XPDL), Business Process Modeling Language (BPML), and Business Process Execution Language.

\section{Analyze}

A student should be able to differentiate, organize, and attribute the following concepts.
- Make comparison, interpretation and contrasting of facts, information, and knowledge to make analytical decisions.

- Analyze different models and point out their similarities and differences.

- Analyze BPM strategies, As-is process models, modeling conditions, triggers, and business rules.

- Analyze different parts \& processes of a system and explain their functioning in a larger context.

- Analyze the context and semantic of available data, information, knowledge, activities.

- Extract hidden meanings of organizational activities, community of practices, processes, etc.

- Analyze the existing BPM strategy to find change factors/element and know how to face change.

- Differentiate between business processes and business rules \& select an appropriate IS system.

- Analyze business process design roles and align them with organizational strategy.

\section{Evaluate}

A student should be able Make judgments based on criteria and standards.

- Compare different situations and develop efficient models choosing an appropriate approach or model and explain the functioning of the model, its benefits and drawbacks.

- Evaluate different modeling tools, techniques, and BPM standards and make appropriate choices based on the context of the projects.

- Verify theories, standards, and models and can assess whether the current process models and their documentation sufficiently represents organizational reality.

- Recognize subjectivity and act accordingly.

- Identify process patterns, develop reference models and predict their performance and consequences.

\section{Create}

A student should be able to perform the following task:

- Create new processes, models, or to modify/re-engineer the existing processes and models, and forecast their impact on organizational performance.

- Create process diagrams of As-is and To-be process diagrams using BPM notations and conduct a gap analysis.

- Devise plan for performance measurement at both enterprise and operational level.

- Innovate new ideas for efficient process models.

- Generate plans for improvement and forecast their impact on organizational performance.

- Create BPMS for an organization using BPMN Extensible Process Definition Language (XPDL), Business Process Modeling Language (BPML), and Business Process Execution Language.

- Innovate new ideas for efficient process models.

\section{Concluding Discussion}

Hyper competition in the globalized business world has forced organizations to adopt high levels of innovation and more sophisticated process management capabilities as efficient process management help them to increase their market share, improve their decision making capacity, and enhance their performance. In recent years, BPM has emerged as a powerful 
competitive tool for organizations. It offers a set of structured methods and technologies to implement on-going crossfunctional process management.

Due to increasing the trend of process oriented IT solutions, computing graduates need to have knowledge about three broad areas: Information Management, Process Management, and ERP Systems. Some of the relevant courses are already included in the existing IT curriculum like Computer Programming, Database Design \& Management, Systems Analysis and Design, Software Engineering, Web Engineering. The students also study courses like Principles of Accounting, Principles of Management, Human Resource Management, and Project Management. However, BPM education that aims to enhance students' knowledge and skills in areas like process modeling, design, improvement, and inter-organizational standards and processes, and the role of technology for achieving efficiency can be very beneficial. In parallel, new jobs have also been introduced in the employment market requiring BPM capabilities. Organizations now prefer hiring of IT graduates equipped with process modeling capabilities. This puts BPM among the most in demand skills in the IT employment market.

Realizing the importance of BPM capabilities, many universities and professional bodies around the globe have started offering degree and training programs in BPM. But, due to the evolving nature of the BPM and associated technologies, no consensus has been established to define what BPM really entails. Academia finds it challenging to define the contents of a BMP course which intends to teach students how to integrate people, technology and processes to produce an agile organization solution.

Developing students' cross-functional integration skill and process-centric thinking is central to BPM Education. For this, students need to learn many of the foundational principles through classroom lecture or textbook reading. Practical assignment can promote students understanding so that they can evaluate, analyze, and apply what they've learned through classroom assignments. Yet, setting up the BMP course objectives is a tedious task. Bloom's Taxonomy has been used in many disciplines for setting up course objectives. Using Bloom's Taxonomy, in this paper we have devised a set of learning objectives of BPM course for IT undergraduate students. These objectives may help educators to standardize the curriculum of a BPM course. Yet, careful selection of course contents, delivery and evaluation methods are required from teachers to optimize their students' learning gain.

Regarding the selection of the contents of BPM course, guidelines and recommendations have been made in literature [61]. ABPMP has also recommended a Core Body of Knowledge. Pasha [31] has identified some additional areas like Knowledge Management, Enterprise Architecture, Service Oriented Architecture (SOP), Extensible Process Definition Language (XPDL), Modeling Language (BPML), and Business Process Execution Language. In addition, material from Internet resources can also be used to achieve the above defined objectives. It is believed, that the learning objective presented in this paper will help academia to standardize the curriculum of a BPM course aiming to develop students' BPM capabilities for translating business strategies into information technology solutions.

\section{REFERENCES}

[1] Morrison, J. 2011. The global business environment: meeting the challenges. $3^{\text {rd }}$ Edition, Palgrave Macmillan.

[2] Fagerberg, J. and Godinho M. M. 2004. Innovation and catching-up. in J. Fagerberg, D. C. Mowery, and R. R. Nelson (Eds.), "Oxford Handbook of Innovation", Oxford: Oxford University Press.

[3] Gantz, J. F., Chute, C., Manfrediz, A., Minton, S., Reinsel, D., Schlichting, W. and Toncheva, A. 2008. The Diverse and Exploding Digital Universe. An IDC White Paper - sponsored by EMC.

[4] Chikova, P. and Hofer, A. 2005. Managing InterOrganizational Business Processes Using an Architecture For M-Business Scenarios. in IEEE International Conference on Mobile Business. 82 - 88 .

[5] Haller, S. and Magerkurth, C. 2011. The Real-Time Enterprise: IoT-Enabled Business Processes. IETF IAB Workshop on Interconnecting Smart Objects with the Internet.

[6] Venkatesh, V. and Balak H. 2012. Adoption and Impacts of Inter-Organizational Business Process Standards: Role of Partnering Synergy. Information Systems Research.

[7] Quan, L. and Tian, G. 2009. A Business Processes' MultiObjective Optimization Model Based on Simulation. In Proceedings of the 2009 International Conference on Information Management, Innovation Management and Industrial Engineering - Volume 04 (ICIII '09), Vol. 4. IEEE Computer Society, Washington, DC, USA, $572-$ 575 .

[8] Peng, M.W., Wang, D.Y.L., and Jiang, Y. 2008. An Institution-Based View of International Business Strategy: A Focus on Emerging Economies. Journal of International Business Studies, 39(5):920-936.

[9] Amah, E. and Baridam, D. 2012. Adaptability and Organizational Effectiveness: A Study of the Nigerian Banking Industry, International Journal of Business and Management Tomorrow. 2(3):1-10.

[10] Harris, M. J. 2008. Realizing the Full Scope of PLM with Business Process Management, IBM Software Group.

[11] Wolf, C. and Harmon, P. 2012. The State of Business Process Management, Business Process Trend Report, BPMTrend

[12] Silver, B. 2010. Uniting Process Architecture and Execution, BPMS Watch, Industry Trend Reports.

[13] Alcácer, J. and Zhao, M. 2010. Local R\&D Strategies and Multi-Location Firms: The Role of Internal Linkages, Working Paper (10-064), Harvard Business School.

[14] Smith, H. and Fingar, P. 2006. Business Process Management: The Third Wave. Meghan Kiffer.

[15] Hernaus, T. 2008. Process-Based Organization Design Model: Theoretical Review and Model Conceptualization. Available at SSRN: http://ssrn.com/abstract $=1719657$

[16] Kroell, T. and Thomas, V. 2011. IT As A Competitive Weapon: Gain Speed, Agility and Cost Efficiency with Your It Infrastructure, White paper: Savvis Markets Infrastructure, Savvis, Inc. 
[17] Porter, M. E. 1985. Competitive Advantage. New York: Free Press.

[18] Goksoy, A., Ozsoy, B. and Vayvay, O. (2012). Business Process Engineering: Strategic Tool for Managing Organizational Change an Application in A Multinational Company, International Journal of Business and Management, 7(2):80-112.

[19] Harmon, P. and Wolf, C (2012). Business Process Centers of Excellence Survey, BPTrends (March, 2012).

[20] Capgemini (2012) Global Business Process Management Report. www.capgemini.com/globalbpmreport

[21] Barjis, J. (March, 2008).The Importance of Business Process Modeling in Software Systems Design, Science of Computer Programming, 71(1):73-87.

[22] van der Aalst, W.M.P., Terhofstede, A.H.M. and Weske, M. 2003. Business process management: a survey. Springer-Verlag Berlin Heidelberg

[23] BPMS Watch. 2010. Uniting Process Architecture and Execution, Industry Trend Reports, Bruce Silver Associates.

[24] Marsan, C. D. 2009. Top 10 Technology Skills, Network World.

http://www.networkworld.com/news/2009/040609-10tech-skills.html

[25] Bandara, W., Chong, S., Indulska, M., Rosemann, M. and Sadiq, S. 2006. Major Issues. In Business Process Management: an Australian perspective. In S. Spencer \& A. Jenkins (Eds.) Proceedings of the 17th Australasian Conference on Information Systems, 6 - 8 December 2006, Australia, South Australia, Adelaide.

[26] Bandara, W., Chand, D. R., Chircu, A. M., Hintringer, S., Karagiannis, D., Recker, J., van Rensburg, A., Usoff, C. and Welke, R. J. (2010). Business Process Management Education in Academia: Status, Challenges, and Recommendations, Communications of the Association for Information Systems: Vol. 27, Article 41.

[27] Seethamraju, R. 2012. Business Process Management: A Missing Link in Business Education, Business

Process Management Journal, 18(3):532 - 547.

[28] Taba, H. 1962. Curriculum Development Theory and Practice. New York, NY : Harcourt Brace \& World.

[29] Tyler, R.W. 1949. Basic Principles of Curriculum and Instruction. Chicago: The University of Chicago Press.

[30] Krathwohl, D. R. 2002. A Revision of Bloom's Taxonomy:An Overview, Theory into Practice, Volume 41, Number 4, Autumn 2002, College of Education, The Ohio State University.

[31] Pasha, M. A. 2012. Developing Business Process Management Capabilities of Undergraduate IT Students, International Journal of Computer Applications, 53(17).

[32] ABPMP Website. 2012. Association of Business Process Management Professionals Web Site.

[33] Moormann, J. and Bandara, W. 2012. Where Are We with BPM Education: A Call for Action. BPTrends. (March, 2012).

[34] Beimborn, D. and Joachim, N. 2011. The Joint Impact of Service-Oriented Architectures and Business Process
Management on Business Process Quality: An Empirical Evaluation and Comparison, Journal Information Systems and e-Business Management Archive, 9(3):333362.

[35] Dumas, M. , Aalst, W. M. P. \& Hofstede, A. H. 2005 Process-Aware Information Systems: Bridging People and Software Through Process Technology, WileyInterscience.

[36] Behara, G. K. 2006. BPM and SOA: A Strategic Alliance. BPTrends. (May, 2006).

[37] Skalle, H., Ramachandran, S., Schuster, M., Szaloky, V. and Antoun, S. (2009). Aligning Business Process Management, Service-Oriented Architecture, and Lean Six Sigma for Real Business Results, IBM Corp.

[38] Beimborn, D. \& Joachim, N. 2011. The joint impact of service-oriented architectures and business process management on business process quality: an empirical evaluation and comparison, Journal Information Systems and e-Business Management archive, 9(3), 333-362.

[39] Leymann, F., Roller, D. and Schmidt, M.T. 2002. Web services and business process management, IBM Systems Journal 21(2):198-211.

[40] Ashton, H. and Kelly, D. 2006. The Business Impact of BPM with SOA: Building a Business Case for BPM with SOA ROI, Upside Research, Inc., Newton, MA.

[41] Mcdonald, M. and Nunno, T. 2007. Creating Enterprise Leverage: The 2007 CIO Agenda. Stamford, CT: Gartner, Inc.

[42] Mcdonald, M. and Aron, D. 2011. Reimagining IT: The 2011 CIO Agenda January 2011. Gartner.

[43] Robi, D. B. 2012. Business Process Management Field Guide, Rapid and Agile Stability, CrossTalk, May/June, 2012:30-35

[44] Hammer, M., Champy, J. (2001). Reengineering the Corporation: A Manifesto for Business Revolution. Nicholas Brealey Publishing, New York.

[45] Eicker, S., Kochbeck, J., and Schuler, P. M. (2008). Employee Competencies for Business Process Management, in W. Abramowicz and D. Fensel (Eds.): BIS. 2008. LNBIP 7, Springer-Verlag Berlin Heidelberg pp. 251-262.

[46] Bruce Silver Associates .2010. Uniting process architecture and execution, BPMS Watch, Industry Trend Reports.

[47] van der Aalst, W.M.P. 2004. Business process management: A Personal View, Business Process Management Journal, 10,2.

[48] Dhookie, V. 2008. To know the future know the past (unpublished).

[49] Delavari, H., Bandara, W., Marjanovic, O. and Mathiesen, P. 2010. Business Process Management (BPM) Education in Australia: A Critical Review Based on Content Analysis, Business Process Management (BPM), 1(1).

[50] Targowski, A., S. and Tarn, J., M. 2007. Enterprise Systems Education in the 21st Century, Information Science Publishing, Idea Group. 
[51] Jæger, B., Rudra, A., Aitken, A., Chang, V. and Helgheim, B. 2010. Teaching Business Process Concepts Using Enterprise Systems in A Globalized Context. HICSS-43: Hawaii International Conference on System Sciences, Kauai, Hawaii.

[52] Pal, R. and Sen, S. 2011. Relevance Of Business Process Management (BPM) Course in Business School Curriculum \& Course Outline, in AMCIS 2011 Proceedings.

[53] Recker, J., Rosemann, M., Indulska, M. and Green, P. 2009. Business Process Modeling: a Comparative Analysis, Journal of the Association for Information Systems 10(4):333-363.

[54] Bandara, W., Indulska, M., Chong, S. and Sadiq, S. 2007. Major Issues in Business Process Management: an expert perspective, $15^{\text {th }}$ European Conference on Information Systems, St. Gallen, Switzerland: University of St. Gallen. 1240-1251.

[55] zur Muehlen, M. 2008. Class Notes: BPM Research And Education - A Little Knowledge is A Dangerous Thing. BPTrends. 5(1): 1-5.

[56] Indulska, M., Recker, J. C., Rosemann, M., and Green, P. 2009. Business Process Modeling: Current Issues and
Future Challenges. Lecture Notes in Computer Science, $5565,501-514$

[56] Bloom, B. S. and David R. K. 1956. Taxonomy of Educational Objectives: The classification of educational goals, by a committee of college and university examiners. Handbook 1: Cognitive domain. New York, Longmans.

[57] Anderson, L. W., \& Krathwohl, D. R. (2001). A Taxonomy for Learning, Teaching and Assessing: A Revision of Bloom's Taxonomy of Educational Objectives: Complete edition, New York : Longman.

[58] Krathwohl, D. R. 2002. A Revision of Bloom's Taxonomy: An Overview, Theory into Practice, 41(4), Autumn 2002.College of Education, The Ohio State University.

[59] Biggs, J. 1996. Enhancing teaching through constructive alignment. Higher Education, 32, 1-18

[60] Recker, J. C. and Rosemann, M. (2009) Teaching Business Process Modelling: Experiences and Recommendations, Communications of the Association for Information Systems 25(32):379-394. 